\title{
A Design Of The Design \& Development Of Safety Features In Stationary \& Mobile Robots In The Industrial Sector
}

\author{
Rajesh Maharudra Patil
}

\begin{abstract}
In this survey article, a short audit of the wellbeing highlights in the field of mechanical autonomies, i.e., with respect to the world of robotics is introduced alongside some structural ideas.
\end{abstract}

Keywords: Robot, Safety, Design, Speed, Barricades

\section{INTRODUCTION}

Robots are reprogrammable, multifunctional, mechanical controllers that ordinarily utilize at least one methods for power: electromechanical, water driven, or pneumatic. Modern robots have been utilized primarily for splash painting, spot-welding, and move and gathering undertakings. A robot plays out its undertakings in a physical territory known as the robot working work envelope. This work envelope is the volume cleared by all conceivable programmable robot developments. This incorporates the region where work is performed by robot tooling.

Any mechanical robot system should have at least $1 \mathrm{arm}$ similar to human hand, which are interconnected arrangements of connections \& fueled joints. Arms are involved controllers which backing or move the wrist/s and the end effectors or grippers. An gripper or the end effector is a frill device explicitly intended for connection to a robot wrist to empower the robot to play out its planned errand. Instances of end-effectors incorporate gripper/s, spot welding weapons \& splash paint firearms. The A N S I R15.06-1986 standards which characterizes a modern robot framework into that which will incorporate mechanical robots, end-effectors, and any hardware, gadgets and sensors required for the whole robot framework to play out its assignments.

Most robots are set up for an activity by the educate andrehash method. In this method, a prepared administrator (developer) ordinarily utilizes a convenient control gadget (usually alluded to as an instruct pendant) to physically key a robot and its undertakings. The programs will consists of the up down instructions, in \& out instructional movements, left \& right instructions, clockwise \& counter clockwise movement instructions, which has to be used in the main code that will be executed for the movement of the robotic system. Robot speeds during these programming sessions are required to be moderate. The ANSI Standard at present

Revised Manuscript Received on September 10, 2019.

Dr. Rajesh Maharudra Patil, Professor \& Head, SB Patil College of Engg., Dept. of Electrical Engineering, GAT, Indapur, Pune, Maharashtra, India.

(Email: rajesh.m.pati1972@gmail.com)

(Email: maharudrapatil.1@gmail.com)

(Email: rmp1971@ rediffmail.com) prescribes this moderate speed ought not surpassing 20 inches per sec (200 $\mathrm{mm}$ per sec).

The very idea of mechanical technology frameworks activities has presented another kind of representative into the modern work environment, the restorative upkeep laborer. This individual is typically present during all activities of an apply autonomy framework and is in charge of guaranteeing proceeding with activity - modifying speeds, amending holds, and liberating jam-ups. The remedial upkeep laborer may likewise be the prepared software engineer who aides a robot through the educate and-rehash system. It is vital for this person to be close to the robot occasionally, which raises worries about their security and the wellbeing of different laborers who may likewise be uncovered.

Ongoing investigations in Sweden and Japan demonstrate that numerous robot mishaps don't happen under typical working conditions yet rather during programming, alteration, testing, cleaning, assessment, and fix periods. During a significant number of these activities, the administrator, software engineer or restorative support specialist may briefly be inside the robot's work space envelope (WSE) while the power is accessible to moving the components of the mechanical robot's frame-worked system.

This rule depicts a portion of the components of good security practices and strategies utilized in the area and establishment of robots and robot wellbeing frameworks, control gadgets, robot programming and representative preparing. An exhaustive rundown of security necessities is given in the ANSI R15.06-1986 Standard.

\section{MOTIVATION BEHIND THE SAFETY SYSTEM ANALYSIS}

The object of a framework wellbeing investigation is to find out the variables which have an orientation on the likelihood of the undesirable events, to examine the manner by which these events occur and, eventually, to create preventive measures to decrease their likelihood.

The logical period of the issue can be separated into two fundamental perspectives:

1. recognizable proof and portrayal of the kinds of brokenness or maladjustment

2. recognizable proof of the groupings of dysfunctions that join one with another (or with progressively "ordinary" events) to lead at last to the 
undesirable event itself, and the evaluation of their probability.

When the different dysfunctions and their outcomes have been contemplated, the framework security examiners can guide their regard for preventive measures. Research here will be founded legitimately on before discoveries. This examination of preventive methods pursues the two principle parts of the framework wellbeing investigation.

The Off Line \& On Line Programming Concepts Used Considering The Safety Point Of View In Mechanical Robots

The robot programming language fills in as an interface between the human client (software engineer) and the robot controller for printed programming. The printed programming utilizing a robot programming language should be possible on-line or disconnected In on-line programming, the controller executes the direction when it is entered and the software engineer can confirm whether the robot executes the ideal assignment. Any inconsistency is, along these lines, amended right away.

On-line writing computer programs is one in which two or beyond what two procedures or occupations can be done simultaneously. In this kind of programming, when one occupation is in advancement, the client can enter the program for playing out the following employments, mimic it and keep it prepared. The minute first activity is over, the working of the subsequent activity begins. Numerous employments can be done simultaneously as it utilizes the parallel handling method.

In the disconnected programming, the robot is detached from the framework. At that point the software engineer needs to compose a program for the robot to do a specific assignment utilizing 3D realistic reenactments, test the program disconnected, in the case of working appropriately or may not work appropriately which after the program has been executed effectively or disconnected w.r.t. the test robot's case. The computing software engineer builds up the program and tests it in a recreated graphical condition without the entrance to the controller. After the software engineer is happy with the rightness of the program, it is transferred to the controller. This technique for programming the robot is canceled as line programming strategy and is particularly valuable w.r.t. the security of the framework. A significant part of the programming should be possible disconnected with a realistic test system of the mechanical robots WSE \& its work space area simulated on the personal computer or on the laptop.

\section{STRATEGIES FOR SAFETY ANALYSIS IN ROBOTICS}

Framework wellbeing investigation might be led previously or after the occasion (from the earlier or a posteriori); in the two cases, the strategy utilized might be either immediate or turn around. A from the earlier investigation happens before the undesirable event. The investigator takes a specific number of such events and decides to find the different stages that may pave the way to them. Paradoxically, an a posteriori examination is completed after the undesirable event has occurred. Its motivation is to give direction to the future and, explicitly, to make any inferences that might be helpful for any ensuing from the earlier investigations.

Despite the fact that it might appear that a from the earlier investigation would be especially more important than an a posteriori examination, since it goes before the occurrence, the two are in actuality integral. Which strategy is utilized relies upon the multifaceted nature of the framework in question and on what is now thought about the subject. On account of substantial frameworks, for example, machines or modern offices, past experience can typically serve in setting up a genuinely point by point from the earlier examination.

In any case, and still, at the end of the day the investigation isn't really faultless and is certain to profit by a consequent a posteriori examination dependent on an investigation of the episodes that happen over the span of activity. As to progressively complex frameworks including people, for example, work movements, workshops or manufacturing plants, a posteriori examination is significantly increasingly significant. In such cases, past experience isn't constantly adequate to allow nitty gritty and dependable from the earlier examination.

An a posteriori investigation may form into a from the earlier examination as the investigator goes past the single procedure that hinted at the episode being referred to and begins to investigate the different events that could sensibly prompt such an occurrence or comparative episodes.

Another manner by which an a posteriori investigation can turn into a from the earlier examination is the point at which the accentuation is set not on the event (whose aversion is the principle reason for the present investigation) however on less genuine occurrences. These episodes, for example, specialized hitches, material harm and potential or minor mishaps, of generally little criticalness in themselves, can be recognized as notice indications of increasingly genuine events. In such cases, in spite of the fact that did after the event of minor episodes, the examination will be a from the earlier investigation as respects progressively genuine events that have not yet occurred.

There are two potential techniques for considering the system or rationale behind the grouping of at least two occasions:

a) The direct, or inductive, technique begins with the causes so as to foresee their belongings.

b) The invert, or deductive, technique takes a gander at the impacts and works in reverse to the causes.

\section{TYPICAL ACCIDENTS}

Coming up next are reported mishaps including robots that happened as of late in Sweden, China, Japan, USA, England.

A specialist endeavored to expel a defectively framed piece from a transport with two hands while as far as possible switching a work material to feed $\&$ to make the evacuation robot to stay in its dynamic position place. The specialist's backing was constrained against the mechanical robot - Then, changing a metal cutting robotic weld 
machine, an administrator was got struck in b/w the machine \& a simply expanded arm of a material feeding system \& the expulsion robot.

A mechanical weld robot one day, went practically amiss and its robotic arm flung or threw a specialist against another $\mathrm{m} / \mathrm{c}$, i.e., took him \& pinned him against another machine - A laborer expelled the front of a working get together robot to recover a fallen part and got his submit the robot's driving mechanism train - A laborer endeavored to recover a section required in a continuous get together without stopping a gathering robot's capacity supply. His hand was gotten b/w the robot's mechanical arm \& the unit which was being gathered later for repairs - An robot arm worked whimsically at the time of a programmed arrangement \& struck the operator who was operating the $\mathrm{m} / \mathrm{c}$ in $\mathrm{b} / \mathrm{w}$ as a result of he died - A kindred representative inadvertently stumbled the power switch while a support specialist was adjusting a get together robot. The robot's arm struck the support laborer's hand.

An administrator performing investigating on a metal plating robot moved the robot hand/arm into a halting position. This set off the robot's crisis stop mode which postponed venting of a pneumatic air stockpiling gadget. At the point when the arrival mode was initiated, the robot's arm moved abruptly and stuck the administrator's thumb against a basic part - A programmed welder robot administrator made a manual change ceaselessly the robot. The person was hit or stuck hard by one of the moving parts of the machine as a result of which a bunch of welding parts got separated \& stuck his head. A material handling robotic machine which was acting upon by the instructions of a robotic administrator suddenly entered into the robotic workspace area during the activities period $\&$ then was stuck hit very had b/w the back part of the robotic machine and a well-being post.

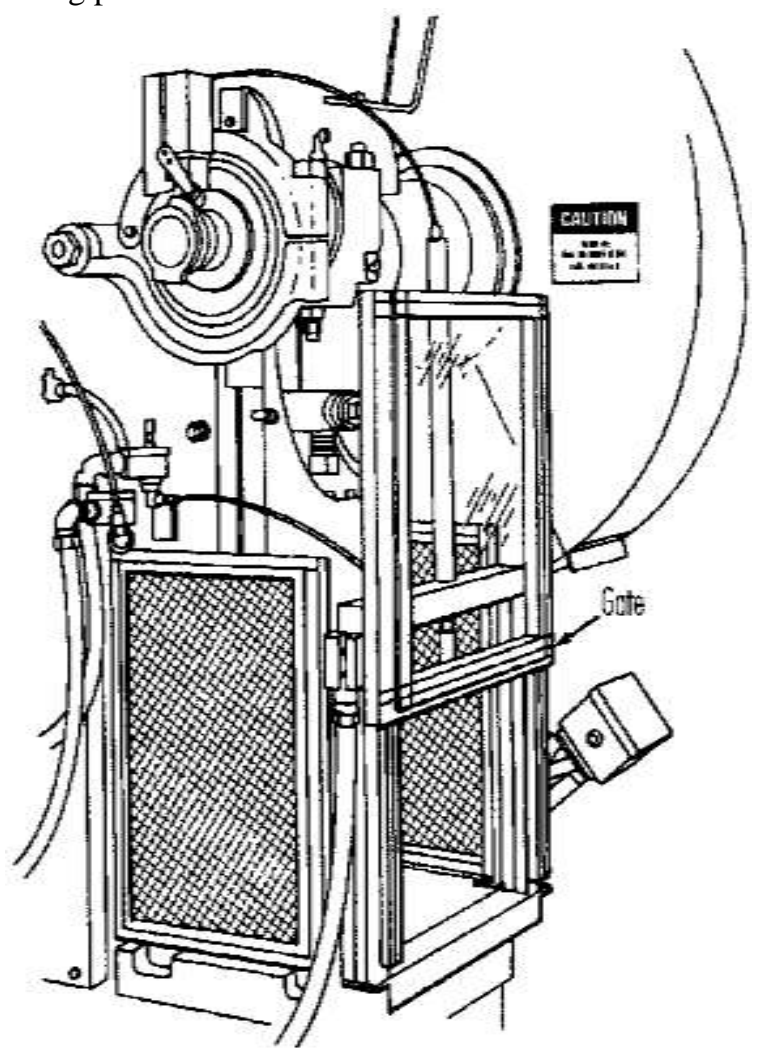

Fig. 1 : Safeguarding robots with humans
The term, gatekeeper implies end is anticipated when vertex $p$ of section An is landed at objective surface $G$ of the work surface $\mathrm{G}$. The work surface $\mathrm{G}$ is going about as the security monitor (like a guardian in a general public premises) and anticipates the further movement. Thus, when an individual place an article on a robotic work-surface, the robotic fingers will feel an upward push/thrust. This force/upward push will be a sign to the mind which thus gives a sign to the robot finger engines to stop the movement of the robotic system further \& maintain a strategic distance from harm to the body.

\section{SAFETY SYSTEMS \& RESULTS}

The best possible determination of a compelling mechanical technology security framework must be founded on danger examination of the activity including a specific robot. Among the elements to be considered in such an examination are the assignment a robot is modified to play out, the beginning up and the programming strategies, natural conditions and area of the robot, necessities for restorative undertakings to support ordinary tasks, human mistakes, and conceivable robot breakdowns. Wellsprings of robot perils include:

1. Human mistakes;

2. Control mistakes;

3. Unauthorized access;

4. Mechanical risks;

5. Environmental risks

6. Electric, pressure driven

7. Power sources w.r.t. pneumatic drives.

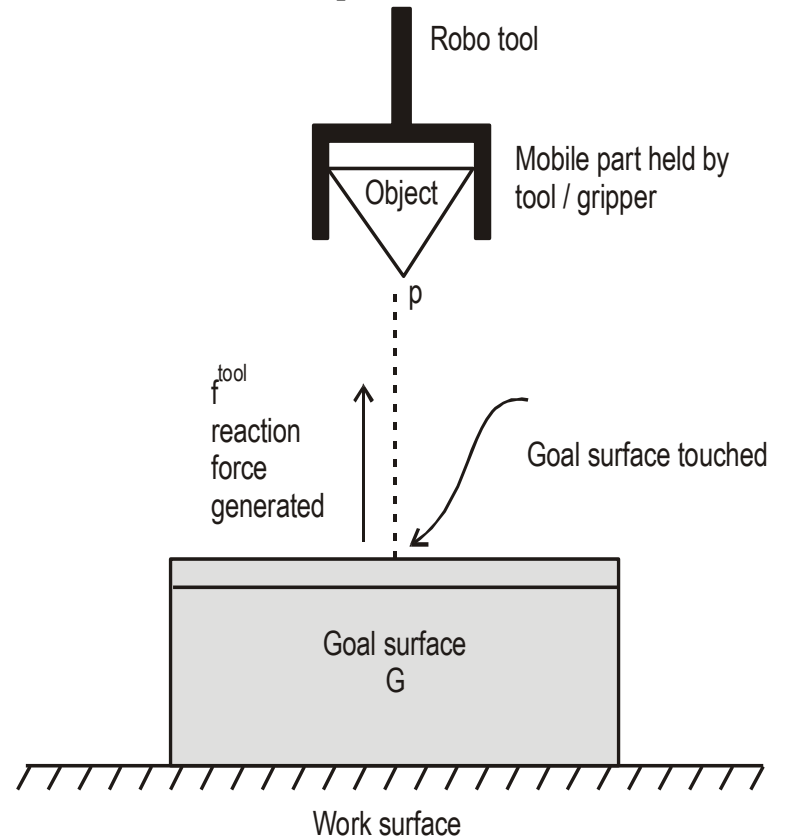

Fig. 2 : Mobile part ' $A$ ' making contact with the goal surface ' $G$ ' of a fixed part

A compelling security framework ensures administrators, engineers, software engineers, support work force, and other people who could be presented to perils related with a robot's activity. A blend of strategies might be utilized to 
build up a viable wellbeing framework. Repetition and reinforcement frameworks are suggested, especially if a robot can make genuine perilous conditions.

\section{GUARDING METHODS:}

\section{6a. Interlocked Barrier Guard}

The interlocked barrier guard will be boundary which is physical in nature $\&$ is present surround the robotic work space envelope fusing entryways outfitted with interlocks. These interlocks are planned so all programmed tasks of the robot and related apparatus will stop when any entryway is opened. Restarting the activity requires shutting the entryway and reactivating a control switch situated outside of the hindrance. A run of the mill handy hindrance is an interlocked fence planned with the goal that entrance through, finished, under, or around the fence is beyond the realm of imagination when the door is shut.

\section{6b. Fixed Barrier Guard}

A fixed hindrance gatekeeper is a fence that requires apparatuses for expulsion. Like the interlocked obstruction watch, it anticipates access through, finished, under, or around the fence. It gives adequate freedom to a laborer between the gatekeeper and any reach by the robot which will include the parts which are held by an end-effector, to play out a particular undertaking under controlled conditions.

\section{6c. Mindfulness Barrier Device}

This is a gadget, for example, a low rail mechanism or it may be a chain which is suspended $\&$ that will characterize a security edge $\&$ is proposed to anticipate coincidental passage into the WSE yet will be moved over, crept under $\&$ or it may be ventured around. Such a gadget is worthy just in circumstances where a risk examination demonstrates that the peril is insignificant and entomb bolted or fixed boundary gatekeepers are not possible. Interlocked or fixed hindrance gatekeepers give a positive security expected to forestall laborer presentation to automated frameworks perils.

\section{6d. Nearness Sensing Devices}

The nearness identifiers that are most regularly utilized in apply autonomy wellbeing are weight tangles and light drapes. Floor mats (weight touchy tangles) and light window ornaments (like varieties of photocells) can be utilized to identify an individual venturing into a perilous region close to a robot. Closeness locators working on capacitance (electrical in nature), may be of ultrasonic type, recurrence of the radio types, laser/s \& and TV standards are presently experiencing dependability testing in research labs in view of perceived restrictions in their ability of distinguishing the nearness of staff.

Albeit a portion of these gadgets are as of now accessible in the wellbeing hardware commercial center, care must be utilized in their choice to guarantee sufficient security and unwavering quality. As of now, such closeness indicators are not suggested for such utilize except if a particular examination affirms their agreeableness for the planned use. Powerful nearness detecting gadgets stop all movement of the robot if any piece of a specialist's body enters the ensured zone. Additionally, they are intended to be safeguard so the event of a disappointment inside the gadget will leave it as it is and may be unaffected or it may be converted into a particular mode in which it will be in waited or in bombed state would not bring about a mishap. Now and again this implies deactivation of the robot. Components which are considered in the determination of such gadgets incorporate spatial impediments of the field, natural conditions influencing the unwavering quality of the field, and detecting field obstruction because of robot activity.

\section{CRISIS ROBOT BRAKING}

Risky robot development is captured by unique stopping mechanisms as opposed to straightforward power may be cut off from the main supply, thus avoiding further damage. Such braking mechanisms will defiantly check the impacts of robot arm inactivity. Removing all power could make dangers, for example, an abrupt dropping of a robot's arm or hurling of a workpiece.

\section{CAPABLE OF BEING HEARD AND VISIBLE WARNING SYSTEMS}

Capable of being heard and obvious cautioning frameworks are not adequate protecting strategies but rather might be utilized to improve the viability of positive shields The motivations behind capable of being heard and obvious sign should be effectively unmistakable.

\section{CONTROL DEVICES}

The accompanying qualities are basic for control gadgets:

a) The principle control board is situated outside the robot framework work envelope in sight of the robot.

b) Readily available crisis stops (palm catches, pull lines, and so on.) are situated in all zones where required. These are unmistakably arranged in effectively found positions and the position recognizable pieces of proof are a noticeable piece of work force preparing. Crisis stops abrogate every single other control.

c) The compact programming control gadget contains a crisis stop.

d) Automatic stop capacities are accommodated irregular robot segment paces and robot crosses past the working envelope.

e) All control gadgets are obviously stamped and named as to gadget reason. Inciting controls are intended to demonstrate the robot's working status.

f) Controls that start power or movement are developed and prepared for incidental activity.

g) Each robot is outfitted with a different electrical switch that can be secured distinctly in the "off" position.

h) User-brief showcases are utilized to limit human mistakes.

i) The control framework for a robot with extensive beginning up time is intended to consider the confinement of capacity to parts having mechanical movement from the 
power required to empower the total robot framework.

j) Control frameworks are chosen and planned with the goal that they keep a robot from consequently endless supply of intensity after electrical power disappointment. The frameworks likewise anticipate dangerous conditions if there should be an occurrence of water driven, pneumatic or vacuum misfortune or change.

k) A robot framework is planned so it could be moved physically on any of its tomahawks without utilizing the framework drive control.

1) All the frame-works w.r.t. the control aspects of the robotic controller should meet the standards that are set by the O S H A 30 CFR 1910 Sub parts denoted by 'S' norms to establish electrical contacts, wiring, dangerous areas \& the related necessity.

\section{INSTALLATION, MAINTENANCE AND PROGRAMMING}

Great establishment, upkeep, and programming practices incorporate the accompanying:

a) The robot is introduced as per the maker's rules and relevant codes. Robots are perfect with natural conditions.

b) Power to the robot fits in with the producer's details.

c) The robot is verified to counteract vibration development and spill.

d) Installation is to such an extent that no extra dangers are made, for example, squeeze focuses with fixed articles and robot segments or stimulated conductor contact with robot parts.

e) Signs \& the markings which are showing the zonal regions of the robotic developmental areas have to be shown unmistakably on the robot itself and, if conceivable, on floors and dividers.

f) Stops are set on the robot framework's tomahawks to restrict its movements under appraised burden and most extreme speed conditions.

g) A lock-out technique is set up and upheld for preventive upkeep or fix tasks.

h) The robot producer's preventive support timetable is pursued thoroughly.

i) A occasional check of all wellbeing basic gear and associations is set up.

j) Stored vitality gadgets, for example, springs and gatherers, are killed before robot adjusting.

k) Only software engineers approach the robotic WSE $\&$ having the full control of mechanical robotic system when it is in the education or training mode.

1) All robot movement started from an encourage pendant utilized by a software engineer situated inside the robot work envelope is liable to the currently having the A N S I moderate speed suggestion of $20 \mathrm{in} / \mathrm{sec}(200 \mathrm{~mm} / \mathrm{sec})$.

\section{OTHER SAFETY FEATURES}

The mechanical robots will be found everywhere all thro' the industries and in any areas where high efficiency and productive work requests have to be made. Utilizing the robots as it may be requires proper planning and any application oriented it should be and after proper execution and having security aspects of the control mechanics in order to abstain from making the complaints to the staffs, programmers, engineers, supporters and mechanical engineers.

\section{FOR WHAT REASON ARE INDUSTRIAL ROBOTS DANGEROUS}

One meaning of robots is "moving programmed machines that are uninhibitedly programmable and can work with next to zero human interface". These sorts of machines are as of now utilized in a wide assortment of uses all through industry and drug, including preparing. Modern robots are in effect progressively utilized for key capacities, for example, new assembling systems (CIM, JIT, lean creation, etc) in complex establishments. Their number and expansiveness of utilizations and the multifaceted nature of the hardware and establishments bring about dangers, for e.g., the accompanying : the developments and arrangements of developments that are practically difficult to pursue, as the robot's rapid developments inside its span of activity regularly cover with those of different machines and gear arrival of vitality brought about by flying parts or light emissions, for example, those radiated by lasers or by water planes free programmability regarding course and speed helplessness to impact by outside blunders (e.g., electromagnetic similarity) human elements.

Many of practical examination that are carried out in the advanced countries such as in Japan will demonstrate that beyond some working mishaps with some of the heavy-duty robots can be put upon the deficiencies in the control circuitry or in the control mechanisms of the controller not properly controlling the system. When similar cases are considered, "man/woman mistake" was in charge of $<30 \%$. Finally, the ending result of this fault finding in the robotic machines is concluded, i.e., that perils which are brought about by framework issues can't be stayed away from by conduct estimates taken by individuals. Creators and administrators subsequently need to give and actualize specialized wellbeing measures

\section{TRAINING}

Successful mishap avoidance projects incorporate preparing. A few to be considered in preparing projects include:

a) Managers and administrators in offices that utilization robots are prepared in the working parts of robots with the goal that they can set and authorize an apply autonomy security approach from an educated perspective.

b) The manager protects that their organization has a composed mechanical autonomy security approach that has been disclosed to all faculty who will work with robots. This wellbeing strategy states by name which faculty are approved to work with robots.

c) Robot programming and support tasks are disallowed for people other than the individuals who have gotten satisfactory preparing in risk acknowledgment and the control of robots.

d) Robot administrators get satisfactory preparing in 
risk acknowledgment and the control of robots and in the correct working methodology of the robot and related hardware.

e) Training is similar with a learner's needs and incorporates the protecting method(s) and the required safe work rehearses essential for safe execution of the student's doled out activity.

f) If it is important for an approved individual to be inside the WSE when a mechanical robot is stimulated, for instance during a programming grouping, preparing is given in the utilization of moderate robot activity speeds and risky area shirking until the work is finished. Such preparing likewise incorporates an audit of crisis stops, and an acquaintance with the robot framework's possibly dangerous vitality sources.

\section{CONCLUSION}

In this article, a concise audit of the wellbeing highlights that can be joined in mechanical technology is being introduced, this is being a survey paper and a great deal of study is being done and displayed, there is no oddity in the work considered, however gives a short data about how to proceed concerning the security includes in the modern robots. As has been appeared, specialized answers for issues may offer ascent to new issues. In spite of the fact that wounds are brought about by machine developments, which are basically specialized ordinarily, this doesn't naturally imply that the potential for their annihilation lies in simply specialized components. Specialized frameworks will proceed to glitch, and individuals will neglect to deal with the circumstances to which these breakdowns give rise. The dangers will proceed to exist, and can be kept in line just by a wide assortment of methods. Enactment and control, hierarchical measures at individual organizations (through preparing, security rounds, chance examination and the detailing of unsettling influences and close to mishaps), and an accentuation on enduring, progressing upgrades are altogether required as supplements to absolutely specialized advancement.

\section{REFERENCES}

1. Craig J, Introduction to Robotics : Mechanics, Dynamics \& Control, Addison Wessely, USA, 1986.

2. Robert, J. Schilling, Fundamentals of Robotics - Analysis and Control, PHI, New Delhi.

3. Klafter, Thomas and Negin, Robotic Engineering, PHI, New Delhi.

4. Fu, Gonzalez and Lee, Robotics: Control, Sensing, Vision and Intelligence, McGraw Hill.

5. Groover, Weiss, Nagel and Odrey, Industrial Robotics, McGraw Hill

6. Ranky, P. G., C. Y. Ho, Robot Modeling, Control \& Applications, IFS Publishers, Springer, UK.

7. Crane, Joseph Duffy, Kinematic Analysis of Robotic Manipulators, Cambridge Press, UK.

8. Manjunath, T.C., (2005), Fundamentals of Robotics, Fourth edn., Nandu Publishers, Mumbai.

9. Manjunath, T.C., (2005), Fast Track to Robotics, Second edn., Nandu Publishers, Mumbai.

10. William Burns and Janet Evans, (2000), Practical Robotics - Systems, Interfacing, Applications, Reston Publishing Co.

11. http://www.wikipedia.org
12. Michael Dipperstein, Run Length Encoding (RLE) Discussion and Implementation.

13. Flusser, J.; Suk, T.; Saic, S., Recognition of blurred images by the method of moments, Image Processing, IEEE Transactions.

14. Bob Bailey, Moments in Image Processing, Nov. 2002.

15. Phillip Coiffette, (1995), Robotics Series, Volume I to VIII, Kogan Page, London, UK.

16. William Burns and Janet Evans, (2000), Practical Robotics - Systems, Interfacing, Applications, Reston Publishing Co.

17. Yoshikawa T., (1984), "Analysis and Control of Robot Manipulators with Redundancy”, Proc. First Int. Symp. on Robotics Research, Cambridge, MIT Press, pp. 735748 .

18. Whitney DE., (1972), "The Mathematics of Coordinated Control of Prosthetic Arms and Manipulators", Trans. ASM J. Dynamic Systems, Measurements and Control, Vol. 122, pp. 303-309.

19. Lovass Nagy V, R.J. Schilling, (1987), "Control of Kinematically Redundant Robots Using $\{1\}$-inverses", IEEE Trans. Syst. Man, Cybernetics, Vol. SMC-17 (No. 4), pp. 644-649.

20. Lovass Nagy V., R J Miller and D L Powers, (1978), “An Introduction to the Application of the Simplest MatrixGeneralized Inverse in Systems Science", IEEE Trans. Circuits and Systems, Vol. CAS-25 (No. 9), pp. 776.

21. [1] World Robotics - Industrial Robots: Statistics, Market Analysis, Forecasts, Case Studies and Profitability of Robot Investment, International Federation of Robotics, Frankfurt am Main, 2011.

22. ISO/TC 184/SC 2 "Robots and robotic devices";

23. working group WG3 "Industrial safety" is one of five active working groups in this subcommittee. See committee web site:

24. http://www.iso.org/iso/iso_technical_committee.html?co mmid $=54138$

ISO 10218 "Robots and robotic devices - Safety requirements for industrial robots", with parts 1 ("Robots") and 2 ("Robot systems and integration"), ISO Copyright Office, Geneva, 2011.

25. M. Hägele, W. Schaaf, and E. Helms, "Robot assistants at manual workplaces: Effective co-operation and safety aspects," In: International Symposium on

26. Robotics ISR 2002 / CD-ROM: Proceedings. October 7 11, 2002, Stockholm, Sweden. Stockholm, 2002.

27. A. De Santis, B. Siciliano, A. De Luca, and A. Bicchi, "Atlas of physical human-robot interaction," Mechanism and Machine Theory, Vol. 43, No. 3, March 2008, p. 253-270.

28. J. Krüger, T. K. Lien, and A. Verl, "Cooperation of human and machines in assembly lines," in: CIRP Annals Manufacturing Technology. 58 (2009), No. 2, pp. 628-646.

29. R. D. Schraft, M. Hägele, and A. Breckweg, "Man and robot without separating systems," In: World of Automation and Metalworking. Frankfurt/M.: VDMA Verlag, 2006, p. 4-5.

30. ISO/TS 15066 "Robots and robotic devices - Industrial safety requirements - Collaborative industrial robots"; ongoing standardization project in draft stage and not publicly available at this time.

31. S. Haddadin, A. Albu-Schäffer, and G. Hirzinger, "SoftTissue Injury in Robotics," IEEE / Robotics and Automation Society, 2010 IEEE International Conference on Robotics and Automation, Anchorage, Alaska USA, 2010, on DOI - 
10.1109/ROBOT.2010.5509854, p. 3426-3433.

32. O. Ogorodnikova, "How Safe the Human-Robot Coexistence Is? Theoretical Presentation," Acta Polytechnica Hungarica, Vol. 6, No.4, p. 51-74 (2009).

33. S. Oberer, R. D. Schraft, "Robot-dummy crash tests for robot safety assessment," IEEE / Robotics and Automation Society: 2007 IEEE International Conference on Robotics and Automation, Rome, Italy, 2007, p. 2934-2939.

34. BG/BGIA Risk Assessment Recommendations according to Machinery Directive - Design of Workplaces with Collaborative Robots, Ed. BGIA - Institute for Occupational Safety and Health of the

35. German Social Accident Insurance, U 001/2009e October 2009 edition, revised February 2011. 